\title{
The effect of screw thread length on initial stability of Schatzker type 1 tibial plateau fracture fixation: a biomechanical study
}

\author{
Ahmet Salduz ${ }^{1 *}$, Fevzi Birisik', Gokhan Polat ${ }^{1}$, Bugra Bekler², Ergun Bozdag ${ }^{2}$ and Onder Kilicoglu
}

\begin{abstract}
Background: This study compares the cyclic loading properties and failure loads of two screw combinations on a synthetic Schatzker type 1 tibia fracture model. Our hypothesis was that after adequate compression with first a partially threaded screw, addition of a fully threaded screw would provide more stability than an addition of a second partially threaded screw.
\end{abstract}

Methods: The Schatzker type 1 tibial plateau fracture model was created. Fixation was obtained in group A $(n=10)$ with two partially threaded screws and in group B $(n=10)$ with one fully threaded screw and one partially threaded screw. Load-displacement evaluation was made at each 1000-cycle interval up to 10,000 cycles. Failure load was identified as the load creating a 2-mm displacement. Two-factor (groups and periods) repeated measurement analysis of variance and independent sample $t$ tests were used.

Results: According to the two-factor repeated analysis, there was no significant difference for periods $(p=0.29)$ and time-period interaction ( $p=0.59$ ) (Wilk's Lambda $F$ value, 1.507 and 0.871 , respectively). In the test of betweensubject effects, there was no significant difference between groups in terms of cyclic loadings $(p=0.06, F=4.065)$. However, in the $t$ test for each 1000-cycle interval, the value of mean displacement in group B was significantly lower than that in group A in the initial, 1000-, 2000-, and 3000-cycle intervals ( $p=0.023,0.031,0.025,0.043$, respectively). The mean displacement and standard deviations increased with the number of cycles. The mean range of displacement initially was $0.66 \mathrm{~mm}$ for group A and $0.36 \mathrm{~mm}$ for group B. The mean range of displacement after 10,000 cycles was $0.79 \mathrm{~mm}$ for group $A$ and $0.44 \mathrm{~mm}$ for group $B$. The mean failure load value was $682 \pm 234 \mathrm{~N}$ for group $\mathrm{A}$ and $835 \pm 245 \mathrm{~N}$ for group B. In independent sample $t$ tests, there were no significant differences between the two groups in terms of failure load $(p>0.05)$.

Conclusions: Obtaining fixation with one partially and one fully threaded screw can minimize displacement at the fracture site at early cyclic loadings.

Keywords: Tibial plateau fractures, Cancellous screw, Thread length, Cyclic loading, Biomechanical test

\section{Background}

The treatment goal for tibial plateau fractures is anatomic reduction and rigid fixation to allow early mobilization. Several fixation methods have been described for rigid osteosynthesis. Percutaneous fixation using a partially threaded cannulated screw is one of the methods, which is reported by some authors with a high

\footnotetext{
* Correspondence: ahmetsalduz@gmail.com

'Department of Orthopedic and Traumatology, Istanbul Faculty of Medicine, Istanbul University, 34093 Istanbul, Turkey

Full list of author information is available at the end of the article
}

rate of success [1-3]. In this technique, generally, partially threaded screws are used and it is recommended that the threaded part of these screws remain distal to the fracture line to obtain compression on the fracture line. The characteristics of screws such as the thread length, diameter, thread pitch, and length of the screws affect biomechanical properties of the fixation [4-12]. This biomechanical strength is important to start early mobilization. Mathur et al. reported that some patients had loss of knee range of motion because of delayed knee mobilization due to the lack of the rigid fixation 
[13]. One reason for lack of rigid fixation may be loss of compression at the fracture site. If the compression at the fracture site is lost, motion between fracture fragments may occur, which may result in non-union or malunion. To our knowledge, there is no study in the literature comparing fixation strengths for different screw combinations. Our hypothesis is that different screw combinations may have different fixation strengths and specifically, addition of a fully threaded screw after obtaining fracture compression using a partially threaded cannulated screw may increase the rigidity of fixation.

\section{Methods}

The cyclic loading properties and failure loads of screw combinations with different thread lengths were compared biomechanically on a Schatzker type 1 tibia fracture model using synthetic bone.

Twenty identical synthetic right tibia bones representing healthy bones without osteoporosis (Synbone, Type: 1149, Synbone AG, Swiss) were used in the study. According to the manufacturer, although their synthetic tibia model is not as strong as the natural bone, it had very favorable feedback from biomechanical testing facilities and it was demonstrated with ballistic testing that it fractures in a manner very similar to the live bone [14] (length $387 \mathrm{~mm}$; tibial plateau width $74 \mathrm{~mm}$; shaft diameter $27 \mathrm{~mm}$; canal diameter $9.5 \mathrm{~mm}$; material: cortical/ hard cancellous bone). We preferred cancellous fixation screws considering the fact that the bone structure of the proximal tibia is mostly cancellous. These 20 bones were divided into two groups of 10 and labeled as group $\mathrm{A}$ and group $\mathrm{B}$.

In order to get standardized results, we needed to standardize screw placement and osteotomy sites. To standardize screw drill holes, first, we drilled two holes in a tibia from lateral to medial with $4.5-\mathrm{mm}$ drill bits, as we would normally do in routine surgeries of Schatzker type 1 tibial plateau fractures. Then, without removing the drills from the bone, we placed them in a durable card box and poured the putty so as to completely encase the bone and the drills. As the polyester steel putty hardened it took the shape of the materials. Then, we pulled out the drills from the bone. Because the putty also hardened around the drills, the location, size, and direction of the drill holes could now be replicated with exact accuracy. This way, when we put a new tibia in the hardened putty template, drills would go through the tunnel inside the putty and we could target them into the bone in a standardized manner (Fig. 1a).

To create an osteotomy template, we first created a template of the proximal tibia by using the same method of encasing the bone about halfway inside the putty and letting it harden around the bone. We decided to create an osteotomy line $1.5 \mathrm{~cm}$ from the lateral edge of the tibial plateau. Then, we sliced the template in a way so that when the bones would be later placed on it, part of the tibia to be osteotomized would hang at the side of the template (Fig. 1b). In this way, a standardized manner of creating Schatzker type 1 fractures (Orthopedic Trauma Association (OTA) classification: 41-B1) and drills holes was established.

After a model was osteotomized, the fragment was repositioned and fixed with combinations of two group screws. All screws were $75 \mathrm{~mm}$ in length and $6.5 \mathrm{~mm}$ in diameter. Two partially threaded cancellous screws were used for group A and one partially threaded screw and one fully threaded screw was for group B (Tasarımmed ${ }^{\circ}$, Istanbul, Turkey). The partially threaded screws in group $\mathrm{B}$ were always placed in the posterior hole, and the fully threaded screws were always placed in the anterior hole. Before the screws were placed, the screw path was tapped and they were tightened with screwdrivers at a torque limit of $1.5 \mathrm{~N}$. This limit was chosen to make sure that all the screws were tightened with the same amount, and the screwdriver with $1.5-\mathrm{N}$ limits is used routinely in our daily practice. Tibia specimens were cut perpendicularly to the long axis of the bone at $13 \mathrm{~cm}$ of the distance from the proximal end. Each sample was embedded in a plastic cylinder, which was $5 \mathrm{~cm}$ in

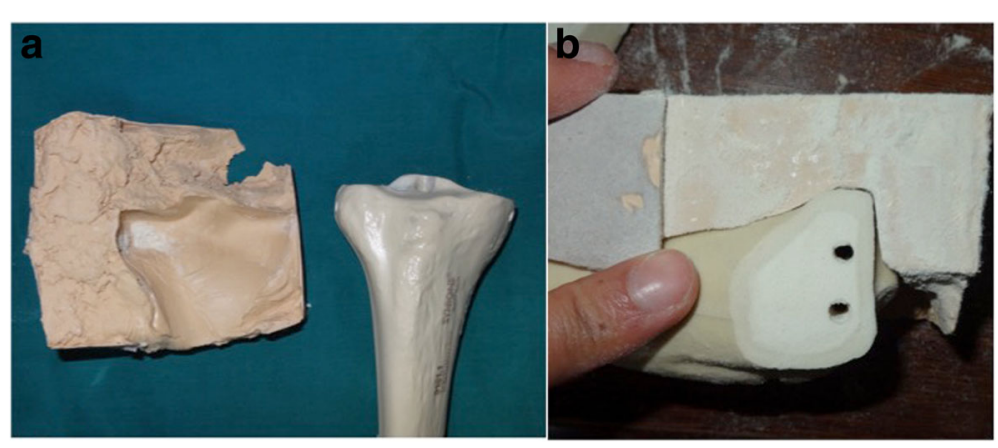

Fig. 1 a Synbone tibia model with the putty template. b The same model after the holes have been drilled and the osteotomy was made 
diameter and $5 \mathrm{~cm}$ in length, using polyester steel putty. This was done so that the distal end of the tibia would be suitable for adapting on a testing machine. X-rays of the specimen are shown in Fig. 2.

\section{Biomechanical testing}

The material test device (MTS 858 Mini Bionix ${ }^{\text {Tu }}$ II) was set up in such a way as to have direct loading on the fracture fragment (Fig. 3). This simulated the action shearing forces on the tibial plateau in full knee extension. We chose this position because it creates the greatest shearing forces on the tibiofemoral joint [15]. A rectangular-shaped piece of rubber was fixed on the fragment of the bone to distribute the load on a greater joint surface. Grid stickers were pasted on both sides of the fracture line on the anterior surface of the tibia. The stickers were registered digitally, and their movements were analyzed using two high-tech cameras that were able to do a 3D analysis (Vic3D 3D Digital Imaging Correlation (DIC), Correlated Solutions Inc.), although we only had a coronal plan analysis of displacement. We defined displacement as $2 \mathrm{~mm}$ of movement along any axis in the space on the basis that intra-articular fractures are usually treated operatively if there is more than $2 \mathrm{~mm}$ of articular step off. Pictures were taken as four frames per second for each 1000-cycle interval and load to failure test.

\section{Cyclic loading (dynamic loading)}

A load to failure test was performed as a preliminary test on a sample from each group to identify the load to be used in cyclic loading tests. The lowest failure load among samples was selected, and two thirds of this value, $300 \mathrm{~N}$, was used as the upper limit in the cyclic loading tests. For the cyclic loading, frequency and preload were determined as $5 \mathrm{~Hz}$ and $10 \mathrm{~N}$, respectively. Between each 1000-cycle interval, the image analysis

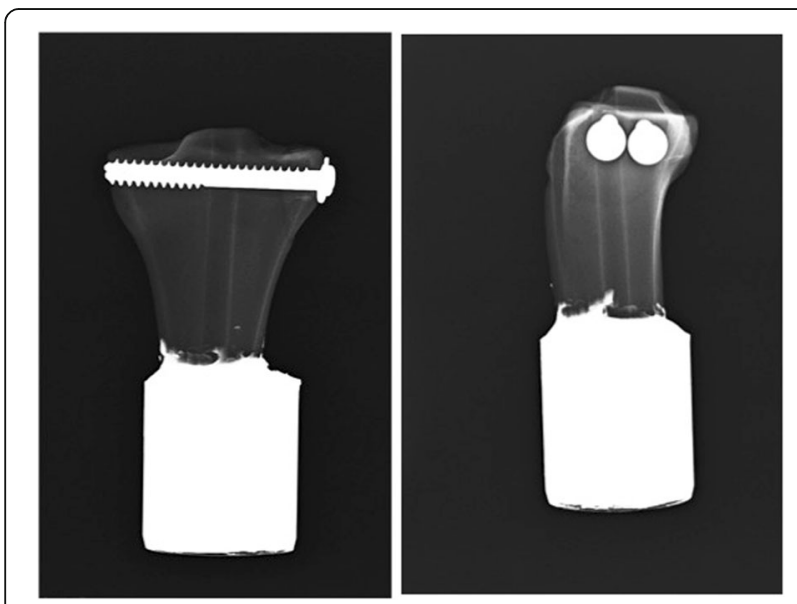

Fig. 2 AP and lateral X-rays of the bone model after screw fixation software recorded a load-displacement evaluation under $300 \mathrm{~N}$ of load. This load was not applied instantly but incrementally in $30 \mathrm{~s}$ with an increase of $10 \mathrm{~N} / \mathrm{s}$ to detect movement with better accuracy. After 10 cyclic loading intervals, failure load values were obtained by continuous loading. The number of cycles was determined as 10,000 cycles according to similar studies in the literature $[7,16,17]$.

\section{Load to failure (static loading)}

Following the cyclic loading, a load to failure test was performed. The loading speed was identified as $5 \mathrm{~mm} /$ min, and the loading was maintained until $3 \mathrm{~mm}$ of displacement. The displacements were detected with an optical camera during this loading phase. The load that caused a 2-mm displacement was identified as the failure load. In one of the load to failure tests, technical errors occurred and meaningful values were not obtained. This measurement was excluded from the study. An example load-displacement graphic, consisting of an initial and 10 cyclic intervals and load to failure tests, is demonstrated in Fig. 4.

\section{Statistical assessment}

Independent sample $t$ tests were used to analyze each period and failure load. Two-factor (groups and periods) repeated measurement analysis of variance was used to simultaneously analyze all cyclic loadings. A $p$ value $<0.05$ was considered as significant. All statistical analyses were performed using SPSS software (version 20.0. Armonk, NY: IBM Corp.) on a personal computer.

\section{Results}

The first statistical analysis that we performed concerned mean displacement values of two groups at specific cycles to assess any differences in stability of the fixation of the fracture site. When each period was evaluated separately with an independent $t$ test, the value of mean displacement in group B was significantly lower than that in group A in the initial, 1000-, 2000-, and 3000 -cycle intervals $(p=0.023,0.031,0.025,0.043$, respectively). The mean range of displacement initially was $0.66 \mathrm{~mm}$ for group A and $0.36 \mathrm{~mm}$ for group B. The mean range of displacement after 10,000 cycles was $0.79 \mathrm{~mm}$ for group A and $0.44 \mathrm{~mm}$ for group B. The mean displacement and standard deviations increased with the number of cycles (Fig. 5). After 4000 intervals, the differences between mean displacements were not statistically significant anymore.

The second statistical analysis concerned differences of mean failure loads to assess the strength of the fixation. The mean failure load value was $682 \pm 234 \mathrm{~N}$ for group A and $835 \pm 245 \mathrm{~N}$ for group B. There were no significant differences between the two groups in terms of 


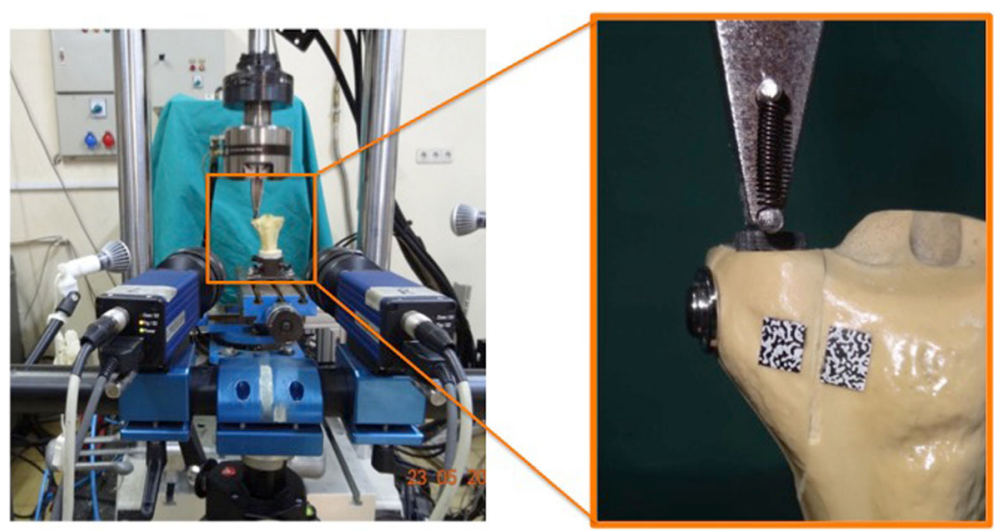

Fig. 3 Experiment setup with two cameras pointed towards the bone model. The figure on the right is the close-up of the model

failure load in independent sample $t$ tests $(p>0.05)$. The mean and $p$ values are shown in Table 1 .

Finally, repeated measurement analysis was performed to make a comprehensive evaluation of our data, which included all cycles. This analysis was made using two factors. Of these two, the within-subjects factor was periods of each 1000 cycle and the between-subjects factor was groups. According to the multivariate tests, there was no significant difference for periods $(p=0.29)$ and time-period interaction $(p=0.59)$ ( $F$ value of Wilk's Lambda test, 1.507 and 0.871 , respectively). In the test of the between-subject effects, there was no statistical difference between the groups as far as how they effect displacement by themselves $(p=0.06, F=4.065)$.

\section{Discussion}

The tibiofemoral joint is subject to different types of forces in different daily activities. The reason of the failure of plateau fractures of the tibia is primarily shearing forces, which cause the fracture fragment to displace, resulting in failure of the osteosynthesis. Therefore, we preferred to test our hypothesis under conditions that create shearing forces on the tibiofemoral joint. The shearing forces are different in various daily activities. They also change with the degree of flexion and extension in the knee joint. The shearing forces are greatest at the last few degrees of extension $[15,18]$. This, however, must be considered with the fact that although shearing forces are greater in extension, there is more contact area to distribute the forces so that the forces applied on unit surfaces may actually be less. According to some studies, walking creates shearing forces in the range of $0.6 \times$ body weight, which means that shearing forces exerted on the tibiofemoral joint of an $80-\mathrm{kg}$ male would be around $480 \mathrm{~N}[15,18]$.

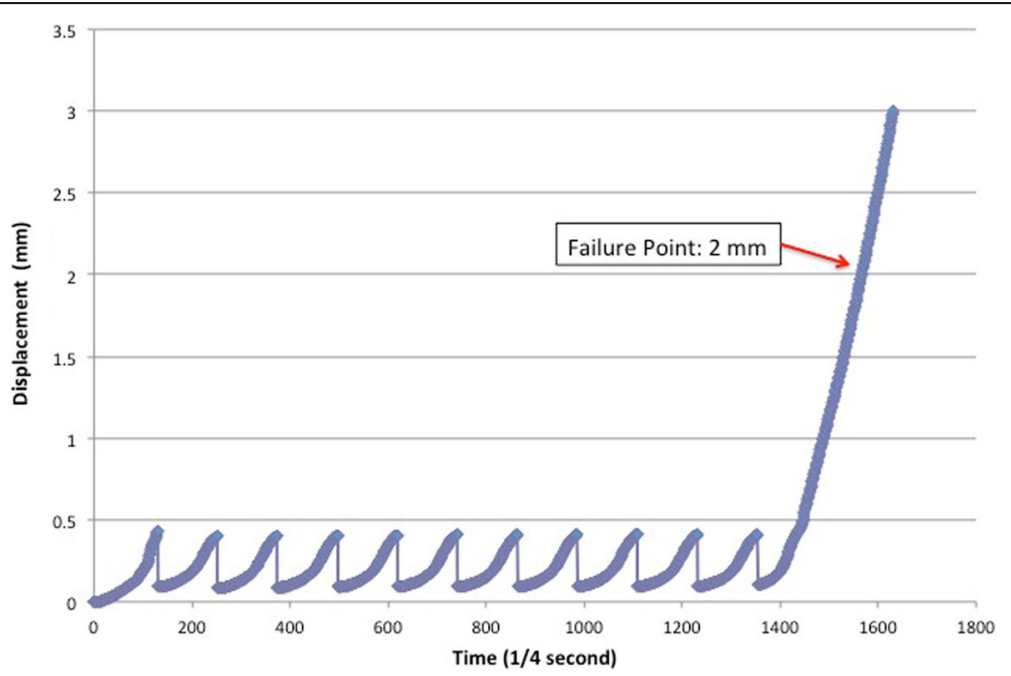

Fig. 4 Time-displacement graphic of one sample. Initial and 10 cyclic loading tests were seen as 11 peaks total. Displacement was increasing because of the load to failure test 


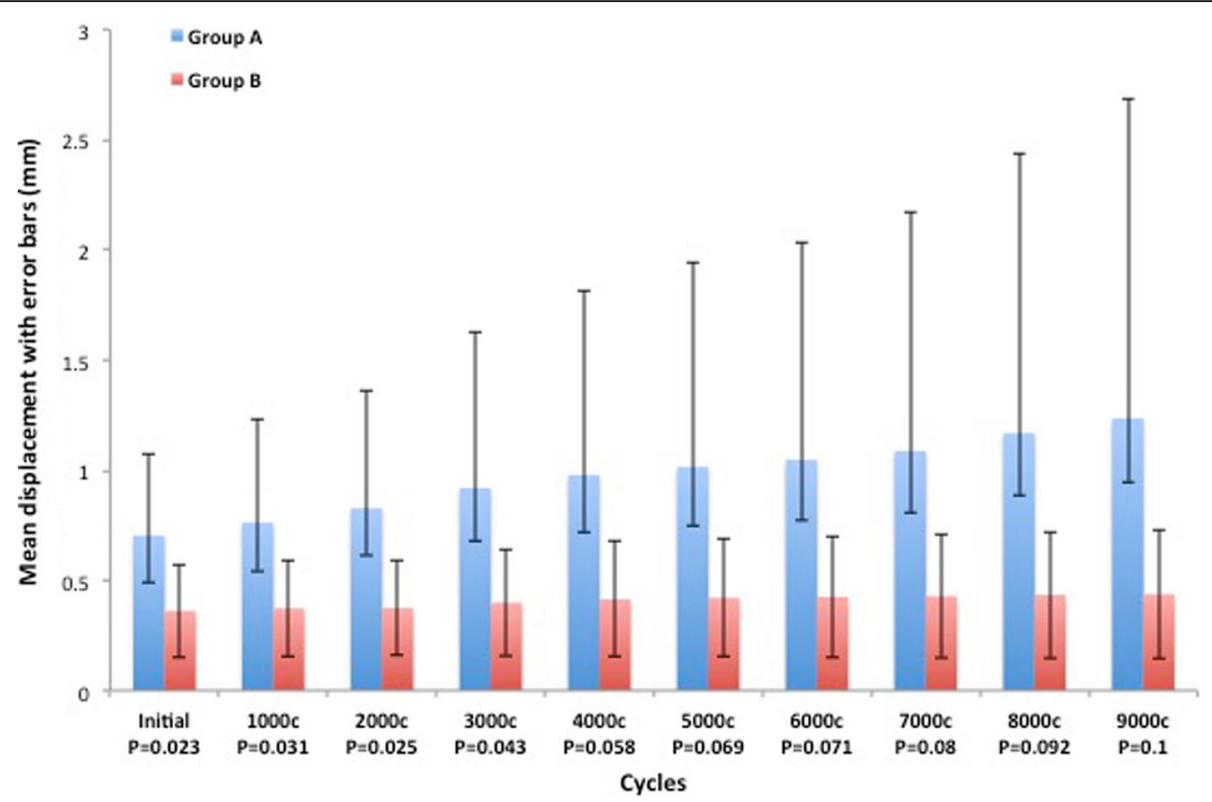

Fig. 5 The graph shows the differences between groups A and B. Up to 3000 cycles, group B has significantly lower displacement values than group A

Cyclic loading test is very important for representing physiological loadings $[7,19]$. We used it to simulate the partial-weight-bearing condition at the early postoperative times. Although late cyclic results are not significantly different in the two groups, our results show that fixation in group $B$ is more durable in early cycles for the same shearing force than that in group A. This may be used to the patients' advantage since in early rehabilitation, patients would benefit from the extra amount of secure fixation provided by the screw combination in group $B$.

Table 1 The mean displacement amount at every 1000-cycle loading phase and the mean failure load values at 2-mm displacement with standard deviations

\begin{tabular}{lccc}
\hline Number of cycles & Group A $(\mathrm{mm})$ & Group B $(\mathrm{mm})$ & $p$ value \\
\hline 0 & $0.66 \pm 0.37$ & $0.36 \pm 0.21$ & 0.023 \\
1000 & $0.71 \pm 0.48$ & $0.37 \pm 0.22$ & 0.031 \\
2000 & $0.73 \pm 0.49$ & $0.37 \pm 0.21$ & 0.025 \\
3000 & $0.74 \pm 0.50$ & $0.40 \pm 0.24$ & 0.043 \\
4000 & $0.75 \pm 0.51$ & $0.41 \pm 0.26$ & 0.058 \\
5000 & $0.75 \pm 0.52$ & $0.42 \pm 0.27$ & 0.069 \\
6000 & $0.76 \pm 0.53$ & $0.43 \pm 0.28$ & 0.071 \\
7000 & $0.77 \pm 0.53$ & $0.43 \pm 0.28$ & 0.08 \\
8000 & $0.78 \pm 0.54$ & $0.43 \pm 0.29$ & 0.092 \\
9000 & $0.79 \pm 0.56$ & $0.44 \pm 0.29$ & 0.1 \\
10,000 & $0.79 \pm 0.56$ & $0.44 \pm 0.29$ & 0.1 \\
Failure load $(M)$ & $682.00 \pm 234.90$ & $835.70 \pm 245.25$ & $>0.05$ \\
\hline
\end{tabular}

The lag technique is still a recognized and accepted technique for optimal primary healing. According to this technique, all threads must cross the osteotomy or fracture site to generate compression. We could not find a paper analyzing different thread configurations at the fracture line in terms of biomechanical features. Our results indicate that after adequate compression with first a partially threaded screw, using a fully thread screw may increase the initial stability of fracture fixation. The loss of the significant differences after 3000 cycles can be explained by the loosening of the screws after cyclic loading for both groups.

While no studies on plateau fractures comparing screw combinations exist, there are some similar studies in the literature, although they do not compare fully and partially threaded screws [20]. Fixation of medial malleoli fractures with fully threaded cortical screw has an advantage compared to unicortical partially threaded lag screws $[21,22]$. On the other hand, there was no significant difference between long and short thread screws for the fixation of the intra-capsular hip fractures by Parker and Ali [23]. Other properties of screws which effect holding power are also investigated in the literature [4, 5, 7, 8, 10, 11, 24-26].

The failure load-displacement amount was chosen as $2 \mathrm{~mm}$ because $2 \mathrm{~mm}$ is a common threshold for treating intra-articular fractures operatively. Furthermore, the number of cycles in this study can be considered low, especially compared to the standard steps/day values required for non-sedentary lifestyle in healthy adults [27]. For a normal adult, 10,000 cycles represent less than a 
week of walking. Nevertheless, 10,000 cycles were enough in our case for failure, which was the endpoint to our experiment. Assuming a person applies bending force 250 times a day for 6 weeks will result in almost 10.000 cycles of this motion. If a healing period of 6 weeks is assumed, the 10,000 cycles is a good estimation for a condition through healing. Additionally, 10,000 cycles was used in the biomechanical studies about fracture fixation in the literature $[7,16,17]$.

Due to its experimental nature, there are several limitations to our study. The first and foremost limitations of this study were the low number of samples and the use of synthetic bone instead of real bone. Another limitation was that we chose to stick our grids right across the midpoint of the fracture line. However, the screws across the fracture line can act as a center of rotation under a lateral shearing force, causing the proximal and distal parts of the fracture to displace differently. Therefore, this study treats the fracture as a single rigid body that shows constant displacement at different corresponding points, which is a simplification of the real fracture mechanics. However, we believe that, although a limiting factor, the difference can be negligible for this sample size.

In real life, the force applied by the body weight on the tibia changes with each degree of flexion and extension and the force applied on the joint surface is different at each point along the gait cycle. However, due to practical limitations, our setup was prepared in such a way as to be an approximation by accepting the load to be constant along the cycle. Furthermore, in real life, the load applied on the joint surface is not the same at every point. However, we could not factor that in our experiment because the cyclic load was applied not by a distal femur as in real life but through a sheet-like hard rubber, which had a smaller surface area than the joint surface. Therefore, the load was concentrated on a smaller area. Since we intend to imitate a real-life biomechanical process, this is a major limitation of our study. The sheet-like rectangular rubber used to distribute the force applied by the machine on the tibia models had a hard consistency to transmit the force without much compression. Still, some amount of the force applied may be lost in compressing the rubber. Insignificant as it may be, it can be considered as a systematic error in our study. In the light of these limitations, we believe further studies with a large number of samples-preferentially real bone-are needed.

\section{Conclusions}

Obtaining fixation with one partially and one fully threaded screw can minimize displacement at the fracture site at early cyclic loadings. This combination might be useful for the Schatzker type 1 tibial plateau fracture during the early rehabilitation period. Although we have failed to demonstrate significant differences at later cycles and failure loads, we have successfully demonstrated that different screw combinations may have different biomechanical properties at the fracture site. With further research, this fact may be translated into meaningful clinical results by adapting specific screw combinations depending on the type of fracture to achieve more secure fixation.

\section{Abbreviation \\ OTA: Orthopedic Trauma Association}

\section{Acknowledgements}

Not applicable.

Funding

Not applicable.

\section{Authors' contributions}

AS and ÖK conceived the design of the study. AS, FB, and GP performed and collected the data and contributed to the design of the study. EB and BB performed the biomechanical tests. AS, OK, and EB prepared and revised the manuscript. All authors read and approved the final content of the manuscript.

\section{Competing interests}

The authors declare that they have no competing interests.

\section{Consent for publication}

Not applicable.

\section{Ethics approval and consent to participate}

Not applicable.

\section{Author details}

${ }^{1}$ Department of Orthopedic and Traumatology, Istanbul Faculty of Medicine, Istanbul University, 34093 Istanbul, Turkey. ${ }^{2}$ Laboratory of Biomechanics and Strength of Materials, Faculty of Mechanical Engineering, Istanbul Technical University, Istanbul, Turkey.

Received: 6 July 2016 Accepted: 14 November 2016

Published online: 22 November 2016

\section{References}

1. Sament R, Mayanger JC, Tripathy SK, Sen RK. Closed reduction and percutaneous screw fixation for tibial plateau fractures. J Orthop Surg. 2012:20:37-41.

2. Sirkin MS, Bono CM, Reilly MC, Behrens FF. Percutaneous methods of tibial plateau fixation. Clin Orthop Relat Res. 2000;375:60-8.

3. Syed MA, Panchbhavi VK. Fixation of tibial pilon fractures with percutaneous cannulated screws. Injury. 2004;35:284-9.

4. Asnis SE, Ernberg JJ, Bostrom MP, Wright TM, Harrington RM, Tencer A, Peterson M. Cancellous bone screw thread design and holding power. J Orthop Trauma. 1996;10:462-9.

5. Chapman JR, Harrington RM, Lee KM, Anderson PA, Tencer AF, Kowalski D. Factors affecting the pullout strength of cancellous bone screws. J Biomech Eng. 1996;118:391-8

6. DeCoster TA, Heetderks DB, Downey DJ, Ferries JS, Jones W. Optimizing bone screw pullout force. J Orthop Trauma. 1990;4:169-74.

7. Firoozbakhsh KK, DeCoster TA, Moneim MS. Effect of cyclical loading on the holding power of surgical screws. Orthopedics. 1994;17:607-11.

8. Gracco A, Giagnorio C, Incerti Parenti S, Alessandri Bonetti G, Siciliani G. Effects of thread shape on the pullout strength of miniscrews. Am J Orthod Dentofacial Orthop. 2012;142:186-90.

9. Magee W, Hettwer W, Badra M, Bay B, Hart R. Biomechanical comparison of a fully threaded, variable pitch screw and a partially threaded lag screw for internal fixation of type II dens fractures. Spine (Phila Pa 1976). 2007;32: E475-9. 
10. Mehta H, Santos E, Ledonio C, Sembrano J, Ellingson A, Pare P, Murrell B, Nuckley DJ. Biomechanical analysis of pedicle screw thread differential design in an osteoporotic cadaver model. Clin Biomech (Bristol, Avon). 2012:27:234-40.

11. Ramaswamy R, Evans S, Kosashvili Y. Holding power of variable pitch screws in osteoporotic, osteopenic and normal bone: are all screws created equal? Injury. 2010;41:179-83.

12. Wang Y, Mori R, Ozoe N, Nakai T, Uchio Y. Proximal half angle of the screw thread is a critical design variable affecting the pull-out strength of cancellous bone screws. Clin Biomech (Bristol, Avon). 2009;24:781-5.

13. Mathur H, Acharya S, Nijhawan VK, Mandal SP. Operative results of closed tibial plateau fractures. Indian Journal of Orthopaedics. 2005;39:108.

14. Bir C, Andrecovich C, DeMaio M, Dougherty PJ. Evaluation of bone surrogates for indirect and direct ballistic fractures. Forensic Sci Int. 2016:261:1-7.

15. Hamill J, Knutzen KM. Biomechanical basis of human movement. 4 ed. Lippincott Williams \& Wilkins; 2015

16. Schildhauer TA, Ledoux WR, Chapman JR, Henley MB, Tencer AF, Routt MC. Triangular osteosynthesis and iliosacral screw fixation for unstable sacral fractures: a cadaveric and biomechanical evaluation under cyclic loads. J Orthop Trauma. 2003;17:22-31.

17. Soin SP, Knight TA, Dinah AF, Mears SC, Swierstra BA, Belkoff SM. Suturebutton versus screw fixation in a syndesmosis rupture model: a biomechanical comparison. Foot Ankle Int. 2009:30:346-52

18. Taylor WR, Heller MO, Bergmann G, Duda GN. Tibio-femoral loading during human gait and stair climbing. J Orthop Res. 2004;22:625-32.

19. Vangsness Jr CT, Carter DR, Frankel VH. In vitro evaluation of the loosening characteristics of self-tapped and non-self-tapped cortical bone screws. Clin Orthop Relat Res. 1981;157:279-86.

20. Hoelscher-Doht S, Jordan MC, Bonhoff C, Frey S, Blunk T, Meffert RH Bone substitute first or screws first? A biomechanical comparison of two operative techniques for tibial-head depression fractures. J Orthop Sci. 2014;19:978-83.

21. Pollard JD, Deyhim A, Rigby RB, Dau N, King C, Fallat LM, Bir C. Comparison of pullout strength between 3.5-mm fully threaded, bicortical screws and 4 . 0-mm partially threaded, cancellous screws in the fixation of medial malleolar fractures. J Foot Ankle Surg. 2010:49:248-52.

22. Ricci WM, Tornetta P, Borrelli J J. Lag screw fixation of medial malleolar fractures: a biomechanical, radiographic, and clinical comparison of unicortical partially threaded lag screws and bicortical fully threaded lag screws. J Orthop Trauma. 2012;26:602-6.

23. Parker MJ, Ali SM. Short versus long thread cannulated cancellous screws for intracapsular hip fractures: a randomised trial of 432 patients. Injury. 2010:41:382-4

24. Frandsen PA, Christoffersen $\mathrm{H}$, Madsen T. Holding power of different screws in the femoral head. A study in human cadaver hips. Acta Orthop Scand. 1984:55:349-51.

25. Kraemer W, Hearn T, Tile M, Powell J. The effect of thread length and location on extraction strengths of iliosacral lag screws. Injury. 1994;25:5-9.

26. Weinstein RB. Orthopedic screw mechanics. http://www.podiatryinstitute. com/pdfs/Update_2011/2011_36.pdf. 2011-36

27. Tudor-Locke C, Bassett Jr DR. How many steps/day are enough? Sports Med. 2004;34:1-8.

\section{Submit your next manuscript to BioMed Central and we will help you at every step:}

- We accept pre-submission inquiries

- Our selector tool helps you to find the most relevant journal

- We provide round the clock customer support

- Convenient online submission

- Thorough peer review

- Inclusion in PubMed and all major indexing services

- Maximum visibility for your research

Submit your manuscript at www.biomedcentral.com/submit

) Biomed Central 